\title{
Persistent Responses to Brief Stimuli: Feedback Excitation among Brainstem Neurons
}

\author{
Wen-Chang Li, ${ }^{1}$ Stephen R. Soffe, ${ }^{1}$ Ervin Wolf, ${ }^{2}$ and Alan Roberts ${ }^{1}$ \\ ${ }^{1}$ School of Biological Sciences, University of Bristol, Bristol BS8 1UG, United Kingdom, and ${ }^{2}$ Department of Anatomy, Medical and Health Science Center, \\ University of Debrecen, Debrecen, Hungary
}

The ability of brief stimuli to trigger prolonged neuronal activity is a fundamental requirement in nervous systems, common to motor responses and short-term memory. Bistable membrane properties and network feedback excitation have both been proposed as suitable mechanisms to sustain such persistent responses. There is now good experimental evidence for membrane bistability. In contrast, the long-standing hypotheses based on positive feedback excitation have yet to be supported by direct evidence for mutual excitatory connections between appropriate neurons. In young frog tadpoles (Xenopus), we show that a small region of caudal hindbrain and rostral spinal cord is sufficient to generate prolonged swimming in response to a brief stimulus. We used paired whole-cell patch recordings to identify hindbrain neurons in this region that actively excite spinal neurons to drive sustained swimming. We show directly that some of these hindbrain neurons make reciprocal excitatory connections with each other. We use a population model of the hindbrain network to illustrate how feedback excitation can provide a robust mechanism to generate persistent responses. Our recordings provide direct evidence for feedback excitation among neurons within a network that drives a prolonged response. Its presence in a lower brain region early in development suggests that it is a basic feature of neuronal network design.

Key words: feedback; locomotion; reticulospinal; rhythm generation; synapses; Xenopus

\section{Introduction}

Persistent neuronal activity in response to brief stimuli has been observed in many higher brain areas and linked to short-term memory (Goldman-Rakic, 1995; McCormick et al., 2003). In animal motor reactions, activity can also far outlast the stimulus that initiates it (Collins et al., 2002); if a rabbit is surprised, it runs off, if a crab is threatened, it raises its claws, if a bird moves, our eyes turn to focus on it. In all of these cases, a brief stimulus leads to a prolonged change in the activity of motor neurons in the CNS that controls the muscles responsible for locomotion, posture, or eye position (Aksay et al., 2001).

There are two familiar explanations for this type of persistent neuronal activity that can be switched on and off by external stimuli (Major and Tank, 2004). In bistability hypotheses, activity results from the intrinsic membrane properties of specialized neurons, which generate prolonged responses to brief excitation. There is direct evidence from studies in a wide range of such neurons that brief excitation can lead to plateau depolarizations and prolonged firing (Hounsgaard and Kiehn, 1989; Kiehn, 1991; Fraser and MacVicar, 1996; Marder and Calabrese, 1996; Lee and Heckman, 1998; Perrier and Tresch, 2005). In reverberation hy-

Received Nov. 4, 2005; revised Feb. 22, 2006; accepted Feb. 25, 2006.

This work was supported by the Wellcome Trust and Hungarian National Research Fund OTKA T037522. We dedicate this work to the memory of Mark Tunstall who made important contributions to understanding swimming in tadpoles but died suddenly in July 2003. We thank Drs. Roman Borisyuk, Malcolm Brown, Gareth Jones, and Steve Coombes for advice on drafts and Alan Blackman, Tim Colborn, and Jenny Maxwell for technical help.

Correspondence should be addressed to Alan Roberts, School of Biological Sciences, University of Bristol, Woodland Road, Bristol BS8 1UG, United Kingdom. E-mail: a.roberts@bristol.ac.uk.

DOI:10.1523/JNEUROSCI.4727-05.2006

Copyright $\odot 2006$ Society for Neuroscience $\quad$ 0270-6474/06/264026-10\$15.00/0 potheses, activity instead persists because neurons in a network feed excitation back onto each other (Lorente de No, 1938; Hebb, 1949; Durstewitz et al., 2000; Seung et al., 2000; Wang, 2001; Koulakov et al., 2002). Reverberation hypotheses have a long history, but we still lack direct evidence for mutual synaptic excitation that is suitable to provide positive feedback, and occurs between neurons forming networks known to generate persistent activity.

To make the problem tractable, we examined persistent activity in the relatively simple neuronal networks that allow a hatchling frog tadpole (see Fig. $1 A$ ) to respond to touch with prolonged swimming (Roberts, 2000). When a Xenopus tadpole is immobilized by blocking neuromuscular transmission, a brief skin stimulus can still trigger motor nerve activity to the swimming muscles lasting for seconds or minutes. This motor activity alternates between left and right sides within the normal swimming frequency range $(10-25 \mathrm{~Hz}$ ) (see Fig. $1 B$ ) (Kahn and Roberts, 1982). Using paired whole-cell recording (Li et al., 2002), our aim was to investigate how this persistent locomotor response is sustained without reflexes by finding the neurons that produce the glutamatergic synaptic excitation that drives spinal activity during swimming (Zhao et al., 1998). In all vertebrates, this excitatory drive is presumed to come from reticulospinal neurons located in the brainstem (Garcia-Rill and Skinner, 1987; Noga et al., 2003; Matsuyama et al., 2004). In Xenopus embryos, previous intracellular recordings and dye fills have shown that possible reticulospinal neurons were active during swimming (van Mier and ten Donkelaar, 1989). Our aim was to find these neurons and determine directly whether they make the mutual excitatory connections expected from reverberation hypotheses 
(Dale and Roberts, 1985) or whether their persistent activity depends on cellular properties such as membrane bistability.

\section{Materials and Methods}

Electrophysiology and anatomy. Xenopus tadpoles at stage 37/38 (see Fig. $1 A$ ) (Nieuwkoop and Faber, 1956)) were briefly anesthetized with $0.1 \%$ MS-222 (3-aminobenzoic acid ester; Sigma, Gillingham, UK), immobilized in $10 \mu \mathrm{M} \alpha$-bungarotoxin (Sigma) saline, and then pinned in a bath of saline (in mM: $115 \mathrm{NaCl}, 3 \mathrm{KCl}, 2 \mathrm{CaCl}_{2}, 2.4 \mathrm{NaHCO}_{3}, 1 \mathrm{MgCl}_{2}, 10$ HEPES, adjusted with $5 \mathrm{~m} \mathrm{NaOH}$ to $\mathrm{pH}$ 7.4). During experiments to localize the region of the CNS that supports sustained swimming, extracellular recordings were made with suction electrodes from ventral roots at intermyotome clefts (Soffe, 1989). The nervous system was transected using fine, etched tungsten pins. NMDA was applied by bath perfusion; D-AP-5 was applied locally through a gravity-fed perfusion nozzle (tip opening, $\sim 120 \mu \mathrm{m}$ ). The dorsal parts of rostral myotomes were removed, and the roof of the nervous system was opened to the neurocoel to improve access. The methods for whole-cell patch using electrodes containing $0.1 \%$ neurobiotin (Vector Laboratories, Burlingame, CA) and Alexa Fluor-488 (Invitrogen, Eugene, OR), extracellular recording, and processing for neuronal anatomy have been described recently (Li et al., 2002, 2004b). Patch pipettes were filled with $0.1 \%$ neurobiotin and 0.1\% Alexa Fluor 488 (Invitrogen) in intracellular solution (in mM: 100 K-gluconate, $2 \mathrm{MgCl}_{2}$, 10 EGTA, 10 HEPES, $3 \mathrm{Na}_{2} \mathrm{ATP}, 0.5 \mathrm{NaGTP}$ adjusted to $\mathrm{pH} 7.3$ with $\mathrm{KOH}$ ) and had resistances of $\sim 10 \mathrm{M} \Omega$. For paired recordings, $1 \mathrm{~mm} \mathrm{MgCl}_{2}$ was usually replaced by $1 \mathrm{mM} \mathrm{CaCl}_{2}$ so that the NMDA-mediated components of excitation could be seen. In many experiments to determine synaptic connections of hindbrain neurons, the left side of the CNS was removed from the second to the 11th postotic segment to improve the access and visibility of more ventral neurons, which were exposed by small cuts to the side of the neurocoel. Antagonists were applied close to the recorded neuron using gentle pressure to solution in a pipette with a tip diameter of $10-20 \mu \mathrm{m}$ or dropped into a $100 \mu \mathrm{l}$ well upstream to the recording chamber. Drugs used were D-AP-5 and 2,3-dioxo-6nitro-1,2,3,4-tetrahydrobenzo[f]quinoxaline-7sulfonamide (NBQX; Tocris Cookson, Bristol, UK), D-tubocurarine, carbachol (Sigma), and dihydro- $\beta$-erythroidine (Research Biochemicals International, Natick, MA). 5-HT (Sigma) was bath applied. Fluorescent imaging was used after recording to check that neuron somata were intact after electrode withdrawal. All figures are quoted as mean \pm SD. Statistical analysis was done by paired $t$ test unless stated otherwise, logtransforming data to normalize where necessary, and performed using Minitab software. All experiments comply with UK Home Office regulations and have been approved following local ethical review.

Modeling. GENESIS software (Bower and Beeman, 1997) was used to build a neuronal network with reciprocal inhibitory half-centers and feedback excitation (see Fig. 6B) (see details in Appendix, Modeling methods). This network modeled a $0.4 \mathrm{~mm}$ length of CNS where neuron numbers (180), longitudinal distributions, and axon lengths were based on anatomical measurements (Roberts, 2000; Li et al., 2001). Excitatory and inhibitory interneurons (iINs) and motoneurons (MNs) were modeled as single compartments. All neurons had modified Hodgkin-Huxley voltage-dependent $\mathrm{Na}^{+}$and $\mathrm{K}^{+}$channels and a passive leak. Kinetic parameters and channel densities were chosen so that the neuron properties were like neurons in the tadpole hindbrain-spinal cord recorded with patch-clamp electrodes (see Fig. $4 A, B, E$ ). They fired once to depolarizing current and also fired a single postinhibitory rebound (anode break) spike when sufficient negative current occurred during depolarization. Axons were represented by conduction delays determined by the longitudinal distance between presynaptic and postsynaptic neurons. At synapses, conductances and currents were modeled. Excitation was of long duration $(\sim 200 \mathrm{~ms})$ as in $0 \mathrm{mM} \mathrm{Mg}^{2+}$ saline and inhibition was short $(\sim 30 \mathrm{~ms})$. The model had symmetrical left and right half-centers. Excitatory axons made synapses on the same side and only inhibitory axons made synapses on the opposite side (see Fig. $6 A, B$ ).
A

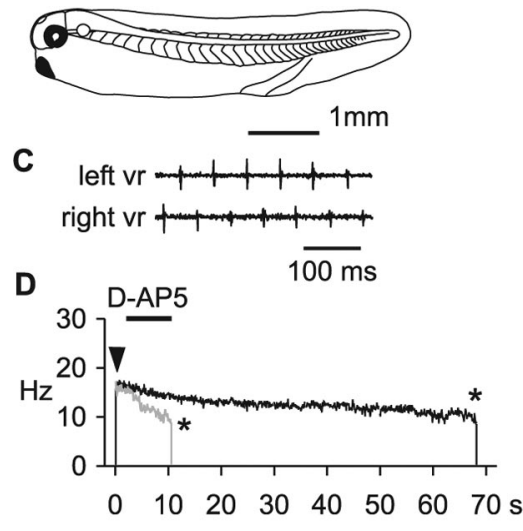

E

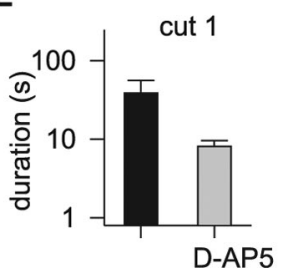

$\mathbf{F}$

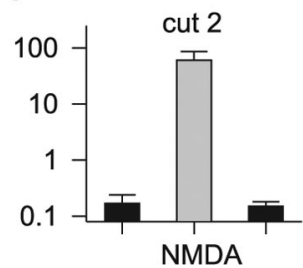

G

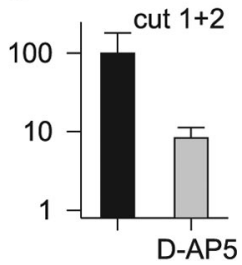

Figure 1. The tadpole, swimming activity, and effects of CNS lesions and antagonists. $\boldsymbol{A}$, Hatchling Xenopus tadpole with CNS and segmented swimming muscles. $\boldsymbol{B}$, Diagrams to show the CNS with the hindbrain, its border with the spinal cord (dashed line), and the segmented swimming muscles ventral. Shaded parts below show what remains after lesions through the whole CNS (arrows; cut 1, cut 2, cut 1+2). C, D, Motor nerve recording (vr) showing alternating activity $(\boldsymbol{C})$ and frequency plot of swimming $(\boldsymbol{D})$ in a tadpole with most of the brain removed (rostral to cut 1) initiated by a $0.5 \mathrm{~ms}$ current pulse to the skin (arrowhead). The plot shows prolonged activity (black), stopping spontaneously after $\sim 70 \mathrm{~s}\left({ }^{*}\right)$ and after a brief $(\sim 10 \mathrm{~s})$ local application of $100 \mu \mathrm{M} \mathrm{D}-A \mathrm{~A}-5$ to the caudal hindbrain (gray, $\left.{ }^{*}\right)$. $\boldsymbol{E}$, Episode durations are shortened after the start of local D-AP-5 application (as in D; based on 19 control and 11 D-AP-5 episodes); each bar represents the overall mean \pm SD of means from five individual tadpoles. $\boldsymbol{F}$, Episodes are very short after spinalization (cut 2), but prolonged swimming is produced by application of $40 \mu \mathrm{m} \mathrm{NMDA} \mathrm{(} n=6$ tadpoles; black bars show control and wash). $\mathbf{G}$, Prolonged swimming in reduced preparations (isolated by cuts 1 and 2 ) is shortened after the start of D-AP-5 application (based on 27 control and 12 D-AP-5 episodes; plotted as in $\boldsymbol{E}$ for 5 individual tadpoles).

\section{Results}

\section{Lesions and pharmacology}

The first step was to localize a region of the nervous system that supports prolonged swimming. After a $0.5 \mathrm{~ms}$ current pulse to the skin, immobilized hatchling tadpoles show swimming motor activity, which alternates on left and right sides and spreads from head to tail (Fig. 1C) (Roberts, 1990). This activity starts at a higher frequency but gradually slows until it stops spontaneously after many seconds. When most of the brain rostral to the seventh rhombomere was removed to leave the spinal cord and only a short part of the hindbrain (Fig. $1 B$, cut 1), swimming was still prolonged $(29.4 \pm 26.5 \mathrm{~s} ; n=21)$ (Fig. $1 D$, black line). We then perfused the NMDA receptor (NMDAR) antagonist D-AP-5 (100 $\mu \mathrm{M})$ locally onto the caudal hindbrain in five of these transected preparations, starting 1-4 s after initiating swimming activity. After the start of this local antagonist application, swimming slowed down rapidly and stopped prematurely (Fig. $1 D$, gray line). Episode lengths were significantly shortened (Fig. 1E) (two to three applications in each of five tadpoles, $p<0.001$ ).

These experiments suggested that the caudal hindbrain plays a crucial role in allowing persistent swimming. Lesions were then used to confirm the importance of this region for persistent 
swimming. If all of the brain was removed (Fig. $1 B$, cut 2), spinal tadpoles swam for $<1 \mathrm{~s}$ after stimulation $(0.2 \pm 0.1 \mathrm{~s} ; n=6)$. As in other vertebrates, these spinal animals could generate prolonged swimming when continuous external excitation was applied (e.g., bath applied $40 \mu \mathrm{M}$ NMDA for $\sim 30 \mathrm{~s}$ ) (Fig. $1 \mathrm{~F}$ ). Thus, although the spinal cord contains the basic pattern generator circuitry to organize swimming motor output (Roberts, 1990), spinal neurons cannot provide sufficient excitation to sustain it. In contrast, an isolated $0.4 \mathrm{~mm}$ length of caudal hindbrain and rostral spinal cord (between cuts 1 and $2 ; n=10$ ) (Fig. $1 B$, shaded) still produced prolonged swimming activity after a brief (0.5 ms) current pulse given to one side of the brain. This swimming slows down after initiation and eventually stops spontaneously. It was no shorter than that produced in the same animals after only cut $1(18.3 \pm 24.9$ and $16.8 \pm 12.6 \mathrm{~s}$, respectively, $n=$ $10 ; p=0.25$ ). As suggested by our initial results (Fig. $1 D, E$ ), prolonged swimming in this $0.4-\mathrm{mm}$-long reduced preparation depends on NMDAR-mediated synaptic excitation. When the NMDAR antagonist D-AP-5 (100 $\mu \mathrm{M})$ was applied $1-4 \mathrm{~s}$ after initiating activity, swimming again slowed down rapidly and stopped prematurely. Episodes in this very restricted region of the CNS were therefore significantly shortened by D-AP-5 (Fig. $1 G$ ) (two to three applications in each of five tadpoles; $p<0.002$ ).

\section{Recordings from hindbrain excitatory interneurons}

The lesion and antagonist experiments show that the caudal hindbrain and rostral spinal cord are sufficient for the CNS to generate prolonged swimming that depends in part on glutamate-mediated excitation. We therefore used whole-cell patch electrodes in this region to find neurons that provide excitatory drive to spinal neurons during swimming. Part of the left side of the hindbrain and spinal cord was removed to improve access to ventral neurons (Fig. $2 \mathrm{~A}$ ), and recordings were initially made in $0 \mathrm{mM} \mathrm{Mg}^{2+}$ saline so the NMDA component of glutamate-mediated excitation could be seen easily. Pairs of connected neurons $<300 \mu \mathrm{m}$ apart were found by stimulating possible presynaptic neurons during loose patch recordings while recording whole-cell from another more caudal neuron that was active during swimming. Presynaptic neurons producing excitation (approximately one in every four tested) were then recorded in whole-cell mode.

We made paired recordings from 115 ventral hindbrain neurons (in 92 tadpoles) and 90 additional caudal central pattern generator (CPG) neurons that were active during swimming. From these recordings, we selected 103, which, for simplicity, we will call hindbrain descending interneurons (hdINs) with the following features (Fig. 2): (1) they were reliably active during swimming (Fig. 2E); (2) they had longer duration action potentials than other CPG neurons (Fig. $2 D, F)$ (hdINs, $1.93 \pm 0.43 \mathrm{~ms}, n=$ 56; CPG neurons, $0.69 \pm 0.2 \mathrm{~ms}, n=47$; measured at $0 \mathrm{mV} ; p<$ 0.001; $F$ test); (3) current-induced hdIN action potentials led to direct, short-latency excitation of the spinal neurons (Fig. 2C) (latency, $1.35 \pm 0.44 \mathrm{~ms}$; range, 0.60-2.40 ms; amplitude, $8.0 \pm$ $5.8 \mathrm{mV} ; n=21$ pairs sampled); in the tadpole, with fine unmyelinated axons usually $<0.2 \mu \mathrm{m}$ in diameter, latencies $<3 \mathrm{~ms}$ in neurons $<300 \mu \mathrm{m}$ apart are likely to be monosynaptic (Li et al., 2004a), (4) they had descending axons revealed by neurobiotin filling (Figs. $2 A, 5 A, C$ ). We rejected 12 other neurons that produced excitation of more caudal CPG neurons but did not have longer duration action potentials and were not active in swimming (so could not contribute to sustaining it).

In a subset of 34 of the best-filled hdINs (Fig. $2 \mathrm{~B}$ ), many (53\%) also had an ascending axon. In these cases, the descending
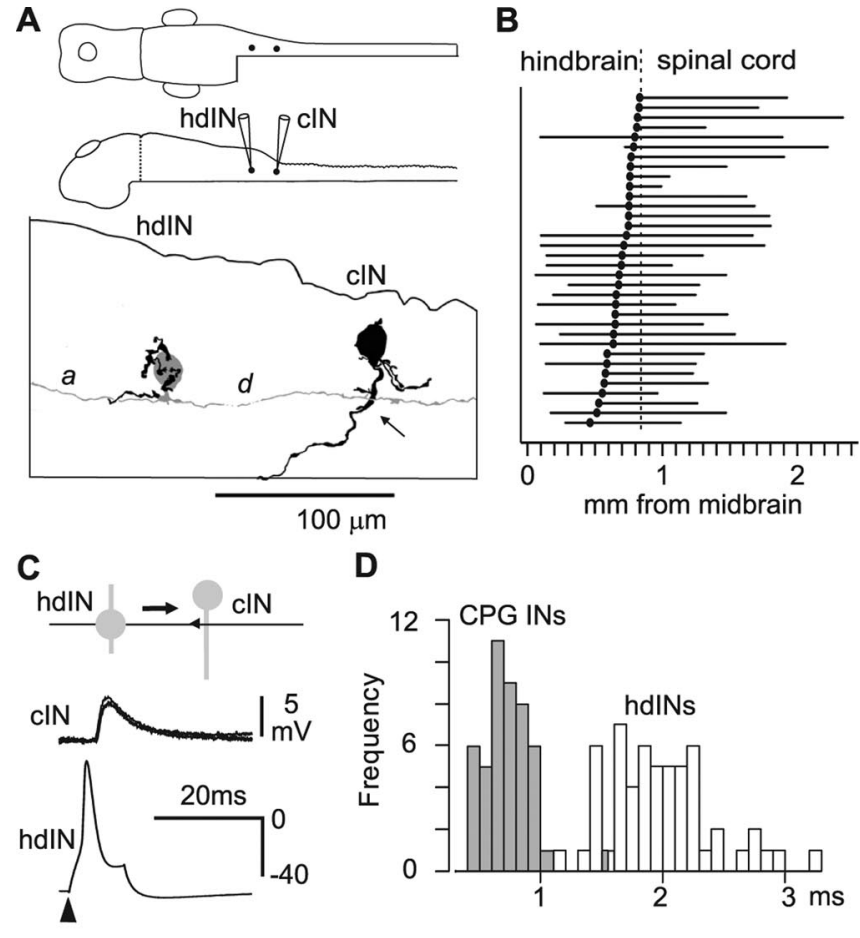

D

E
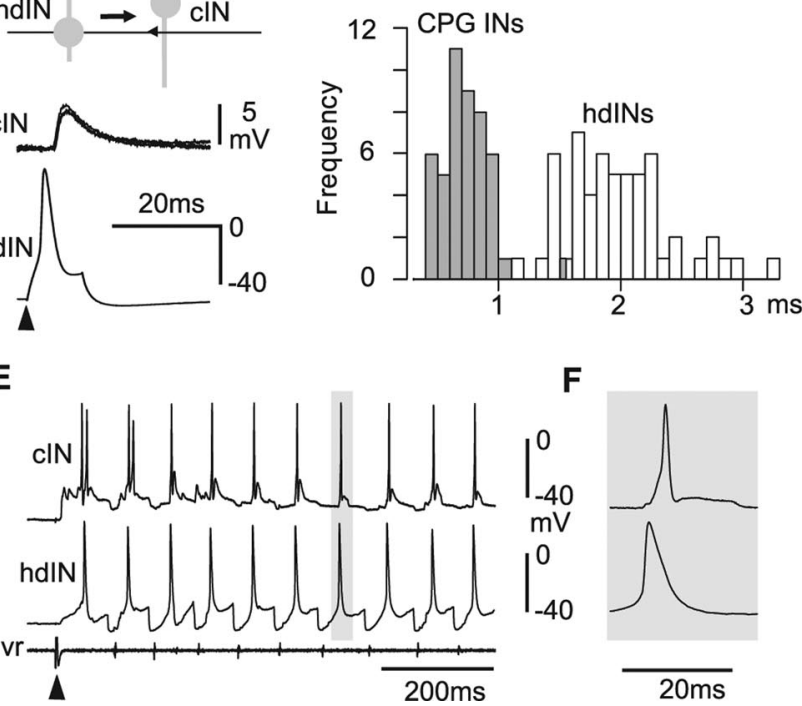

$\mathbf{F}$

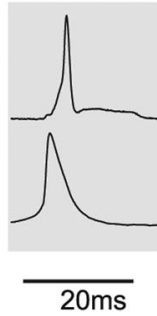

Figure 2. Anatomy, connections, and activity of hdINs. A, Diagrams of the CNS and detailed tracing of an hdIN (gray) with ascending (a) and descending (d) axons and possible contact onto a spinal commissural IN (cIN; arrow). B, Soma positions (dark circles) and axon projections of 34 excitatory hdINs with complete and traceable anatomy found in paired recordings. Some hdINs have both descending and ascending axons. C, Current induced action potential (in hdIN; $\boldsymbol{A}$ ) leads to excitation of cIN (3 overlapped traces; latency, $1.5 \mathrm{~ms}$ ). D, Action potential durations are longer in hdINs than CPG INs (measured at $0 \mathrm{mV}$ ). $\boldsymbol{E}$, The hdIN in C fires one spike per cycle during swimming initiated by a current pulse to the skin at the arrowhead. $\boldsymbol{F}$, Gray section in $\boldsymbol{E}$ expanded to show hdIN spikes are longer in duration and earlier in the cycle than cIN spikes.

axons were significantly longer $(0.80 \pm 0.30$; maximum, 1.53 $\mathrm{mm})$ than the ascending axons $(0.47 \pm 0.17$; maximum, 0.70 $\mathrm{mm} ; n=18 ; p=0.001)$. The spinal neurons excited by hdINs were identified as CPG neurons using anatomical features revealed by neurobiotin filling (Roberts, 2000). There were 22 motoneurons with peripheral axons, 35 descending INs, four commissural INs, three ascending INs, and 26 unidentified rhythmic neurons.

The hdINs therefore directly excite spinal neurons that are active during swimming. To observe their "normal" activity during swimming, 26 hdINs (in 31 tadpoles) were recorded with the hindbrain intact and in $1 \mathrm{~mm} \mathrm{Mg}^{2+}$ saline. They showed activity typical of spinal neurons (Figs. 2E, 3A) (Soffe et al., 1984). On each cycle, they were tonically depolarized, fired one relatively long action potential (Fig. $2 F$ ), and received midcycle inhibition. This reciprocal inhibition and also the recurrent inhibition that occurs shortly after firing on some cycles are much clearer as outward currents in voltage-clamp recordings at a holding potential of $0 \mathrm{mV}$ (Fig. 3 B, C) (Li et al., 2004c). In recordings from 

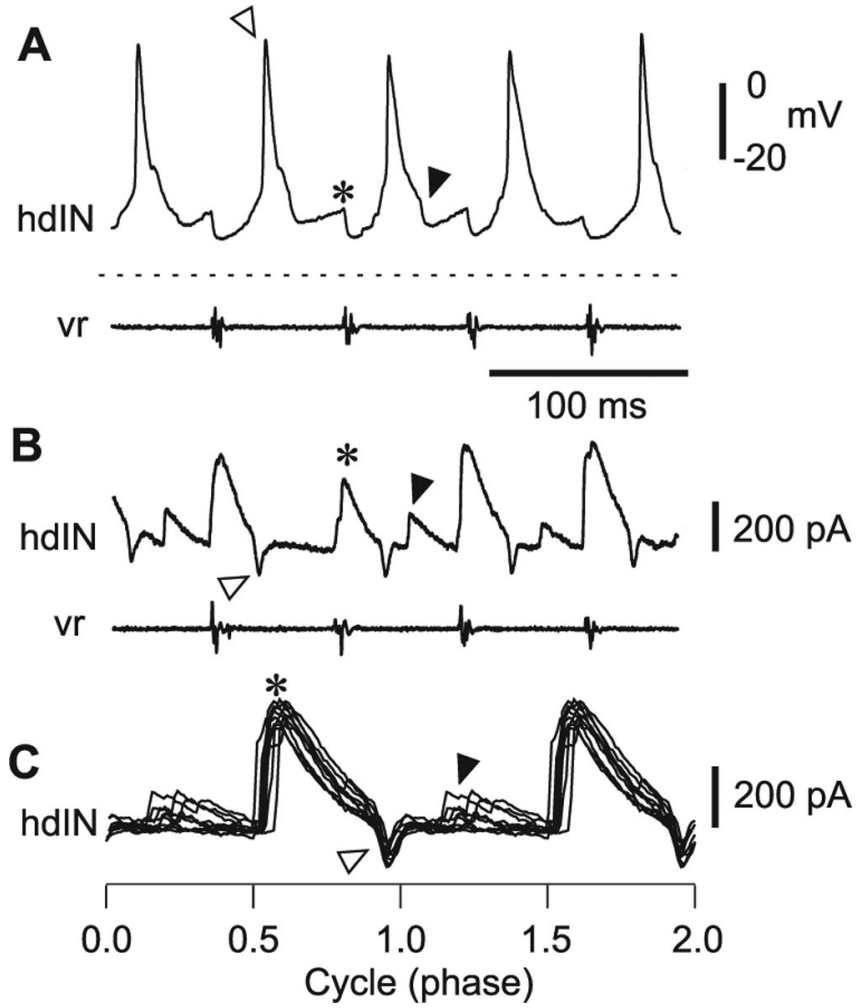

Figure 3. Activity and inhibition in hdINs during swimming. $\boldsymbol{A}$, hdIN on the right side is depolarized from resting potential (dots), fires a single spike (open arrowhead) followed by recurrent inhibition (black arrowhead) and midcycle, reciprocal inhibition $\left({ }^{*}\right)$ in time with left side ventral root burst (vr). B, Same hdIN in voltage clamp at $0 \mathrm{mV}$ showing corresponding, small inward current at spike, strong midcycle IPSC, and smaller IPSC after some spikes. C, Superimposed phase plots show reliable midcycle IPSCs and smaller, less reliable recurrent IPSCs after inward current of action potential.

12 hdINs during swimming, midcycle IPSCs were very reliable, occurring on virtually all cycles. Smaller recurrent IPSCs were also present in each hdIN but were less reliable (occurring in $62 \%$ of the first 20 swimming cycles after the initiation stimulus).

The timing of spikes in hdIN and spinal CPG neurons was measured over $\sim 20$ swimming cycles, using the start of the ventral root burst as a reference (Fig. $2 E)$. Mean hdIN firing $(n=16)$ was $2.7 \mathrm{~ms}$ earlier in the cycle than for spinal neurons active during swimming ( $n=12$; two-sample $t$ test, $p=0.03)$. This was equivalent to $3.4 \%$ of the mean cycle period $(80 \mathrm{~ms})$. Because the circuitry of the tadpole is so simple, it is reasonable to suggest that hdINs, with spikes occurring early on each cycle of swimming, are a major source of excitation to spinal neurons during swimming.

\section{Cellular properties of hindbrain excitatory interneurons}

To investigate membrane bistability hypotheses, we examined the cellular properties of 35 hdINs. When depolarizing current was injected, while recording in $1 \mathrm{mM} \mathrm{Mg}^{2+}$ saline, individual hdINs generally fired a single action potential, even at currents well above threshold (Fig. 4A), like some other Xenopus spinal neurons (Aiken et al., 2003) and some mammal dorsal horn neurons (Prescott and De Koninck, 2002). At the end of current pulses, the membrane potential returned quickly to near rest with no evidence of any depolarizing plateau potential that outlasted the injected current (Kiehn, 1991). This was also true when repeated firing was induced by repeated current pulses $(20 \mathrm{~Hz}, 30$ spikes, equivalent to 30 swimming cycles) (Fig. $4 C$ ), even when tested with applied $10 \mu \mathrm{M} 5$-HT $(n=8)$ or the muscarinic agonist
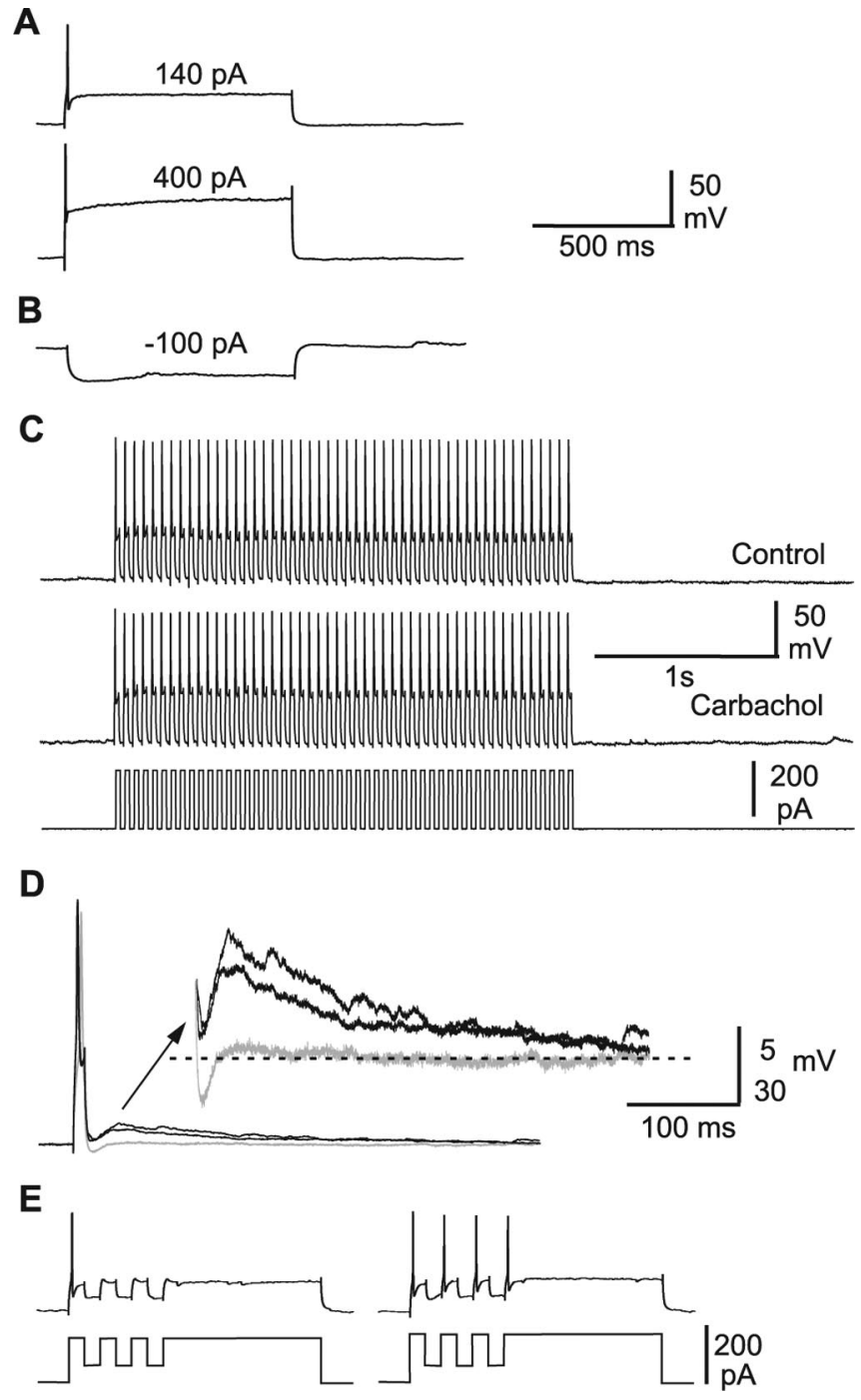

Figure 4. Responses of hdINs to injected current. $\boldsymbol{A}$, hdIN fires only once to threshold and superthreshold-positive current and shows no evidence of plateau potentials at the end of the current pulse. $\boldsymbol{B}$, Negative current pulses at rest do not show any evidence of rebound firing. $\boldsymbol{C}$, Repetitive firing induced by repeated current pulses does not lead to a plateau potential even in $20 \mu \mathrm{m}$ carbachol. $\boldsymbol{D}$, When a $10 \mathrm{~ms}$ current pulse evoked an action potential, an hdIN in $0 \mathrm{Mg}^{2+}$ saline shows a depolarizing potential that outlasts the current pulse (2 black traces), but this was blocked by application of $2.5 \mu \mathrm{m} \mathrm{NBQX}$ plus $25 \mu \mathrm{M} \mathrm{D}$-AP- 5 plus $20 \mu \mathrm{m} \mathrm{D}$-tubocurarine (gray trace). The inset is shown at a higher gain. $\boldsymbol{E}$, If an hdIN is sufficiently depolarized by positive current (right), it will fire again on rebound after short superimposed negative currents. Same scales in $\boldsymbol{A}, \boldsymbol{B}$, and $\boldsymbol{E}$.

carbachol $(10-50 \mu \mathrm{M} ; n=7)$, which can induce plateau responses (Hounsgaard and Kiehn, 1989; Fraser and MacVicar, 1996; Svirskis and Hounsgaard, 1998).

In $0 \mathrm{mM} \mathrm{Mg}^{2+}$, responses to current injection were similar, except that small depolarizing potentials were seen in some hdINs immediately after short $10 \mathrm{~ms}$ current pulses that evoked action potentials (Fig. $4 D)(n=24$ of 90). However, these depolarizations were blocked by applied glutamate receptor and ACh receptor (AChR) antagonists (1.6-2.5 $\mu \mathrm{M}$ NBQX, 16-25 $\mu \mathrm{M}$ D-AP-5, 1-3.3 $\mu \mathrm{M}$ dihydro- $\beta$-erythroidine, or $20 \mu \mathrm{M}$ D-tubocurarine; $n=8$ ), suggesting that they were glutamatergic and cholinergic EPSPs rather than plateau potentials (Li et al., 2004a).

Because postinhibitory rebound has been proposed as a part of the mechanism for rhythm generation in the tadpole central pattern generator, leading to neuron firing after midcycle recip- 
rocal inhibition (Roberts and Tunstall, 1990), we examined hdIN responses to negative current pulses. When given at the resting membrane potential, such pulses did not induce rebound firing in any neurons tested ( $n=18$ ) (Fig. $4 B$ ), but if sufficient negative current was injected during depolarizing current, hdINs fired single rebound action potentials $(n=15)$ (Fig. 4E).

\section{Excitatory connections between hindbrain interneurons}

If hdINs drive swimming activity but show no evidence of membrane bistability or postinhibitory rebound from rest, do they make the mutual excitatory synaptic connections expected from reverberation hypotheses? Of crucial significance for a feedback mechanism to sustain swimming activity was the finding that many hdINs had both descending and ascending axons (Figs. $2 A, B, 5 A, C)$. Although descending axons permit the feedforward excitation of more caudal neurons, as we described above, the ascending axons provide an anatomical pathway for feedback excitation that could allow hdINs to make mutual synaptic connections.

Our first evidence confirmed that individual hdINs do make synaptic contacts from both their ascending and descending axons. By making sequential paired recordings, we showed that the same, individual hdINs ( six hdINs in six tadpoles) excited postsynaptic neurons both rostral and caudal to themselves. However, the most compelling and direct evidence came from simultaneous recordings from pairs of hdINs. We found 47 pairs (in 23 tadpoles) with the long-duration action potentials characteristic of hdINs, where a current induced action potential in one neuron led to direct, short-latency excitation of the other. In $28 \%$ of these pairs ( 13 pairs in 13 tadpoles), in which the more caudal neuron also had an ascending axon, we found reciprocal, excitatory connections between the neurons. A current induced action potential in either neuron led to a short latency $(1.65 \pm 0.51 \mathrm{~ms}$ ) (Li et al., 2002) EPSP in the other (Fig. $5)$. This demonstration of direct, reciprocal excitatory connections between hindbrain neurons that are active during swimming establishes a clear basis for feedback excitation.

\section{Pharmacology of excitation from hdINs}

The pharmacology of excitation from neurons with a descending axonal projection has been defined ( $\mathrm{Li}$ et al., 2004a). The excitatory neurons that we studied previously lay in both the hindbrain and spinal cord and were all called descending interneurons. Those lying in the hindbrain we are now calling hdINs. The excitation from these neurons is unusual, because both hdINs and other spinal descending INs corelease glutamate and acetylcholine to induce fast AMPA receptor and nicotinic AChR-mediated currents and long NMDAR-mediated currents. Consequently, excitation from hdINs is only blocked by joint application of glutamate and acetylcholine receptor antagonists. The excitation between pairs of hdINs showed a similar pattern of corelease to that described previously; EPSPs were again blocked only by joint application of
B
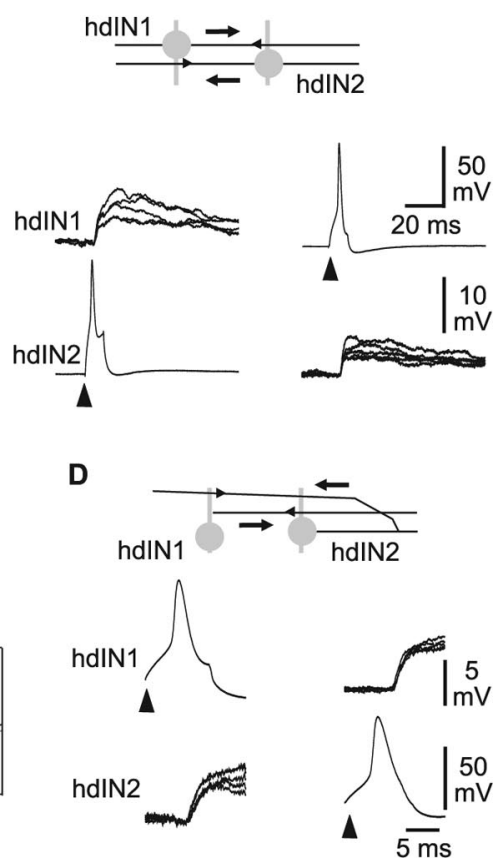

Figure 5. Hindbrain neurons make reciprocal excitatory connections with each other. $\boldsymbol{A}$, Two hdINs, both with descending (d) and ascending (a) axons. Possible contacts are indicated by arrows. $\boldsymbol{B}$, Intracellular current injection (at arrowheads) shows that each hdIN excites the other. $C$, Another hdIN pair with possible contacts (arrows). The descending axon of hdIN 2 branches to ascend $\left(^{*}\right)$. D, Reciprocal excitation as in $\boldsymbol{B}$. Diagrammatic drawings in $\boldsymbol{B}$ and $\boldsymbol{D}$ summarize the anatomy and interactions between hdIN pairs (triangles represent excitatory synapses).

A

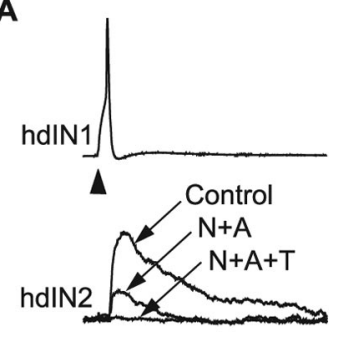

B

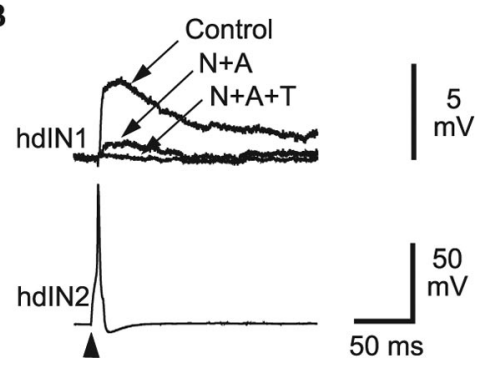

Figure 6. Corelease of glutamate and acetylcholine at synapses between hindbrain neurons. $\boldsymbol{A}$, Current injection into hdIN1 (at arrowhead) excites hdIN2. This excitation is reduced compared with control by application of $2.5 \mu \mathrm{M} \mathrm{NBQX}$ and $25 \mu \mathrm{M} \mathrm{D}-\mathrm{AP}-5(\mathrm{~N}+\mathrm{A})$ but is only blocked by additional application of $20 \mu \mathrm{m}$ D-tubocurarine $(\mathrm{N}+\mathrm{A}+\mathrm{T}) . \boldsymbol{B}$, Excitation between the two hdINs is reciprocal: current injection into hdIN2 (arrowhead) also excites hdIN1. Again, excitation is only blocked by combined application of glutamate and cholinergic antagonists. All traces are averages of $>10$.

glutamate and acetylcholine receptor antagonists $(n=6$ of 6 pairs tested) (Fig. 6).

\section{Consequences of feedback excitation}

The significance of mutual excitation between hdINs was emphasized by observations made in $0 \mathrm{~mm} \mathrm{Mg}^{2+}$ saline, in which a lack of the normal $\mathrm{Mg}^{2+}$ block of NMDAR makes preparations more excitable. Brief current pulses evoking one action potential in the stimulated neuron led to a feedback EPSP in 24 of 90 hdINs (Fig. $4 D$ ). The probable basis for this is illustrated by one paired recording from two hdINs in which reciprocal excitation existed (Fig. 7A). Here, the excitation in one direction was sometimes strong enough to make the other hdIN fire an action potential. When this occurred, a feedback EPSP appeared in the stimulated neuron. Some hdINs can therefore excite other hdINs sufficiently 
A

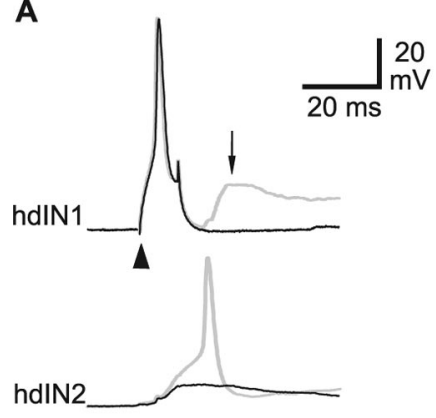

B

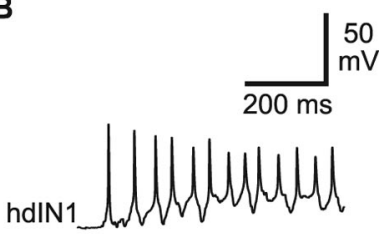

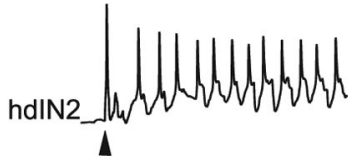

Figure 7. Consequences of feedback excitation. $A$, Current injection into hdIN1 (arrowhead) can excite hdIN2 (black trace). If hdIN2 excitation leads to firing (gray trace), a feedback EPSP appears in hdIN1 (gray trace, arrow). B, Current injection of $10 \mathrm{~ms}$ into hdIN2 (arrowhead) can produce an action potential in hdIN1 and start swimming in the whole tadpole.

strongly to make them fire, and as a result they receive feedback excitation through reciprocal connections. Indeed, in the 47 pairs of hdINs recorded in which excitatory connections were found, a single action potential was evoked by the monosynaptic EPSP in six cases. In the other cases, the excitation from a single hdIN cannot be strong enough to evoke a postsynaptic action potential.

In some cases, in $0 \mathrm{~mm} \mathrm{Mg}^{2+}$ saline, intracellular current injection ( $n=10$ neurons) or extracellular stimulation of single hdINs with a loose-patch electrode applied to the soma under visual control $(n=29)$ could trigger rhythmic activity in the whole swim circuit (Fig. $7 B$ ). In $1 \mathrm{~mm} \mathrm{Mg}{ }^{2+}$ saline, this was only seen in 2 of 35 hdINs, suggesting that summation of excitation from several hdINs is normally needed for postsynaptic neurons to reach firing threshold. We assume that this is the case when sensory stimuli initiate swimming and the whole neuronal network becomes active.

\section{Modeling networks with feedback excitation}

Our evidence establishes that hdINs make reciprocal excitatory synapses but how might they function to produce persistent reverberatory activity? A long-standing hypothesis provides one possible explanation for rhythm generation by left and right halfcenters in the caudal hindbrain and spinal cord of the tadpole (Fig. 8A) (Roberts and Tunstall, 1990). When swimming is initiated by sensory excitation, the neurons in the left half-center fire once and drive the muscles to contract. The excitatory neurons provide long-duration NMDAR-dependent feedback excitation that eventually sums cycle-by-cycle to produce a steady depolarization (Dale and Roberts, 1985). However, it does not immediately cause additional firing, because the neurons, like typical hdINs, are difficult to excite when depolarized (Fig. 4A). They therefore remain depolarized while the right half-center fires, producing contraction and also reciprocal inhibition of the opposite side. This inhibition hyperpolarizes the neurons in the left half-center, which then recover their excitability and fire again on rebound. They can do this only because the long, NMDARmediated excitation has outlasted the reciprocal inhibition. The depolarization produced by the feedback excitation is therefore crucial because, unlike some rhythm generators (Satterlie, 1985), rebound firing after inhibition is not seen from rest in tadpole spinal neurons (Fig. 4B). If model neurons have properties like hdINs, then simulated networks of six neurons forming a single "segment" (connected as in Fig. 8A) (see details in Appendix, Modeling methods) can generate robust alternating "swimming"

activity after a brief synaptic excitation to both half-centers (Roberts and Tunstall, 1990).

Starting with this excitatory feedback and postinhibitory rebound hypothesis, we built a physiologically realistic, 180neuron population model of the 0.4-mm-long isolated caudal hindbrain-rostral spinal cord region that we have shown can produce prolonged swimming (Fig. $1 B, G$, cut $1+2$ ). This model was then used to evaluate the importance of the axonal projection patterns of hdINs in providing feedback as well as feedforward excitation to drive swimming. The basic connections were an extension of the six-neuron, half-center model (Fig. $8 \mathrm{~A}$ ), but now the model had length: each type of neuron formed a longitudinal column, and interneurons made connections from their longitudinal axons onto neurons they pass (Fig. $8 B$ ). We first tested a network with only feedforward descending excitation in which the excitatory hdINs had only descending axons and connections. Swimming activity occurred in the model but failed to persist, first rostrally and then totally (Fig. $8 C, E$ ). We then added feedback excitation by giving the hdINs the additional ascending axons and excitatory connections that we discovered. When feedback excitation was present, swimming activity was reliable and persistent (Fig. 8D,E)

\section{Discussion}

Animal motor systems produce many different types of longlasting or even continuous activity. Where activity is the normal state, as in the heartbeat or in respiration, individual muscle cells or neurons often have pacemaker properties (Cymbalyuk et al., 2002; Pena et al., 2004; Del Negro et al., 2005). In cases in which such activity is driven by neuronal circuits, the neurons may still act as pacemakers but also have other properties that lead to continuous activity, like the ability to fire on rebound from reciprocal inhibition when at rest (Satterlie, 1985). These normally active systems contrast with many locomotor circuits that are only active after stimulation and where the normal state is inactive. Most vertebrate spinal central pattern generators fall into this group (Stein et al., 1997). They can organize alternating rhythmic motor output only while they receive continuous "tonic" excitation and are not active without it. In experiments, this excitation typically comes from repetitive electrical stimulation of brainstem locomotor regions (Noga et al., 2003) or applied chemical excitants [like NMDA and 5-HT (Butt et al., 2005)]. In life, this excitation is assumed to come from reticulospinal neurons in the brainstem (Orlovsky, 1970a, 1970b), but the neurons and mechanisms generating tonic drive are only beginning to be understood (Viana Di Prisco et al., 1997). We have now investigated the very simple nervous system of the hatchling frog tadpole, in which persistent swimming is initiated by a brief sensory stimulus (Roberts, 1990). As a result, we succeeded in locating appropriate excitatory neurons in the tadpole hindbrain that provide direct excitation to spinal neurons during swimming, allowing us to explore how they may enable sustained activity.

Our whole-cell patch recordings from pairs of neurons in the frog tadpole provide direct evidence that hindbrain and rostral spinal cord neurons, with descending axons on the same side, supply feedforward excitation to spinal neurons including motoneurons during swimming, confirming previous suggestions (Dale and Roberts, 1985; Roberts and Alford, 1986). Surprisingly, this excitation is mediated by the corelease of glutamate and acetylcholine (Li et al., 2004a), and since this discovery, similar corelease has been found in mammalian motoneurons (Mentis et al., 2005; Nishimaru et al., 2005). We found that more than half of 
these excitatory neurons located in the hindbrain also have ascending axons. These neurons are therefore able to produce feedback (ascending) as well as feedforward (descending) excitation. Such connections are not rare, because they were present in $28 \%$ of cases in which excitatory synapses were found.

In the frog tadpole, we have shown that the spinal cord can only produce persistent activity to brief stimuli when the caudal hindbrain is attached. Local NMDA antagonist application to the caudal hindbrain blocks persistent activity in preparations transected in the mid-hindbrain. The importance of the caudal hindbrain is endorsed by our finding that when this short region is isolated surgically with the most rostral segment of spinal cord, prolonged swimming responses are still produced and depend on the activation of NMDAR. Within this restricted region of the simple tadpole CNS, we recorded 103 excitatory hindbrain neurons that fire reliably during swimming, have long action potentials, and directly excite spinal neurons active in swimming. These hindbrain neurons have surprisingly consistent anatomy, properties and activities suggesting that they form a distinct class.

If, as we propose, these neurons play a crucial role in driving prolonged swimming responses that can last for many seconds or even minutes after sensory stimulation, how can they sustain their own activity? We found no evidence for plateau potentials or any other long-lasting cellular bistability that could explain their persistent activity during swimming (Hounsgaard and Kiehn, 1989; Kiehn, 1991; Fraser and MacVicar, 1996; Marder and Calabrese, 1996; Lee and Heckman, 1998; Perrier and Tresch, 2005). Plateau responses generated by calcium activated nonspecific (CAN) currents have been widely implicated in the generation of prolonged responses, including those in lamprey reticulospinal neurons (Viana Di Prisco et al., 1997, 2000). We examined the effects of the reported CAN current antagonist flufenamic acid (W.-C. Li, unpublished observation). The initiation of swimming was disrupted, but flufenamic acid had a range of other effects on neuronal properties in the tadpole. Therefore, although we cannot rule out a possible role for CAN currents, our results do not provide any direct support. We were also unable to induce rebound firing after hyperpolarizing current pulses given at rest. This means that postinhibitory rebound from the resting potential cannot initiate rhythmic activity as it does in some networks like the one controlling swimming in the marine mollusc Clione (Satterlie, 1985). In tadpole hdINs, postinhibitory rebound only occurs when neurons are depolarized above their firing threshold (Fig. $4 E$ ). In contrast, our direct evidence from paired whole-cell patch recordings now clearly demonstrates feedback synaptic excitation between these hindbrain neurons. The possible consequence of these connections was illustrated by the finding that current injection into individual hdINs could trigger long-lasting activity in themselves and the whole swimming circuitry. It seems most likely that these connections provide a basis for positive feedback to support persistent swimming activity. Our modeling demonstrates the feasibility of this proposal.

Clearly, positive feedback resulting from the mutual excitatory connections that we found between hdINs will have to be constrained, and this will happen through both cellular and circuit factors. Most importantly: the strongly adapting firing properties of hdINs (Fig. 4A) make it difficult for them to fire more than once if simply depolarized by excitation. The possibility of repetitive firing would also be limited by feedback (recurrent) synaptic inhibition from the swimming circuit on the same side (Li et al., 2004c). Finally, there is delayed, reciprocal inhibition from the opposite side. Paradoxically, this will first inhibit firing but then provide cycle-by-cycle excitation through postinhibitory rebound during the long feedback excitation. Together, these mechanisms permit persistent swimming activity to reverberate between left and right sides after a brief stimulus as we have demonstrated in our model network (Fig. 8). Because rhythm generation can occur in a single side of the tadpole CNS (Soffe, 1989), there are likely to be additional mechanisms underlying rhythmic activity; however, whatever these mechanisms are, they need to be sustained by synaptic feedback excitation.

The hdINs we studied are probably homologues of adult brainstem reticulospinal neurons that activate locomotion in mammals (Noga et al., 2003). They lie in a ventral position in the caudal hindbrain and have short dendrites and descending ipsilateral axonal projections to the spinal cord. Some also have ascending axons. Similar neurons have been described in developing Xenopus and zebrafish, where they are considered to be reticulospinal neurons (Nordlander et al., 1985; Metcalfe et al., 1986; van Mier and ten Donkelaar, 1989). In adult lamprey, intracellular recordings have also shown that such neurons are active during swimming (Viana Di Prisco et al., 1997; Viana Di Prisco et al., 2000; Brocard and Dubuc, 2003) and excite spinal neurons directly by activating glutamate receptors (Ohta and 
Table 1. Values used to define rate constants for the voltage-dependent $\mathrm{Na}^{+}$and $\mathrm{K}^{+}$channels

\begin{tabular}{|c|c|c|c|c|c|c|}
\hline \multirow[b]{2}{*}{ Constant } & \multicolumn{4}{|l|}{$\mathrm{Na}^{+}$} & \multicolumn{2}{|l|}{$\mathrm{K}^{+}$} \\
\hline & $\alpha_{\mathrm{m}}$ & $\beta_{\mathrm{m}}$ & $\alpha_{\mathrm{h}}$ & $\beta_{\mathrm{h}}$ & $\alpha_{\mathrm{n}}$ & $\beta_{\mathrm{n}}$ \\
\hline$A$ & -3 & 4 & 0.07 & 1 & -0.1125 & 0.03125 \\
\hline$B$ & -0.1 & 0 & 0 & 0 & -0.0025 & 0 \\
\hline$C$ & -1 & 0 & 0 & 1 & & 0 \\
\hline$D$ & 30 & 55 & 55 & 25 & & 55 \\
\hline$F$ & -10 & 18 & 20 & -10 & & 80 \\
\hline
\end{tabular}

Table 2. Number of excitatory (hdIN), inhibitory (iIN), and motoneurons (MNs) in the model at each longitudinal position

\begin{tabular}{clll}
\hline & \multicolumn{2}{l}{ Number of neurons } & \\
\cline { 2 - 4 } Position $(\mu \mathrm{M})$ & hdIN & iIN & MN \\
\hline $0-100$ & 18 & 18 & 10 \\
$100-200$ & 16 & 18 & 12 \\
$200-300$ & 16 & 18 & 12 \\
$300-400$ & 14 & 16 & 12 \\
\hline
\end{tabular}

Rostral $=0$.

Table 3. Properties of central and sensory synapses

\begin{tabular}{lcrc}
\hline & Glutamate & Glycine & Sensory \\
\hline Reversal potential (mV) & 0 & -80 & 0 \\
Peak conductance (nS) & 0.5 & 10 & 15 \\
Opening time constant (ms) & 1 & 1 & 1 \\
Closing time constant (ms) & 75 & 6.5 & 75 \\
Probability of synapse & 0.3 & 0.2 & 1 \\
\hline
\end{tabular}

When an axon reached or passed a neuron, synapses are made with probabilities given.

Grillner, 1989). What is surprising is that the clearest evidence for discrete groups of reticulospinal neurons controlling motor activity comes from the very specialized brainstem nuclei controlling vocal organs and electric organs in teleost fish (Dye and Meyer, 1986; Bass and Baker, 1990; Kawasaki, 1994). In general, and in diverse vertebrate groups from fish to mammals, reticulospinal neurons play an important role in activating locomotion, but it is still unclear in most cases whether they are driven or sustain their own activity. It is interesting to note that the hdINs directly excite spinal motoneurons as well as interneurons. Although direct, monosynaptic connections from reticulospinal neurons to spinal motoneurons are clearly established in mammals (Peterson et al., 1979), their significance during locomotion compared with indirect connections via propriospinal relays remains unclear.

\section{Conclusion}

Feedback excitation may not be the only brain mechanism for sustained motor responses. However, our modeling of the tadpole hindbrain and spinal cord neuronal networks (based on the ability of hdINs to fire on rebound from reciprocal inhibition when they are depolarized by long-duration feedback excitation) supports it as one mechanism contributing to prolonged activity. Similar feedback excitation mechanisms have been modeled extensively and are proposed to be of general importance in other persistent neuronal responses (Durstewitz et al., 2000; Seung et al., 2000; Wang, 2001; Koulakov et al., 2002), unless membranebased mechanisms like plateau potentials are present (Kiehn, 1991; Loewenstein et al., 2005). Our findings now supply what has been crucially lacking in these proposals: direct experimental evidence for mutually excitatory connections between appropriate brain neurons.

\section{Appendix}

Modeling methods

GENESIS software (Bower and Beeman, 1997), version 2.1 with an integration time step of $0.1 \mathrm{~ms}$, was used and run under Red Hat 7.0 or Debian 3.0 Linux on Pentium IV personal computers to build the neuronal network model of the central pattern generator network spanning the hindbrain-spinal cord border of the Xenopus tadpole.

\section{Properties of neurons and their distributions}

The small and electrotonically compact neurons of the tadpole (Wolf et al., 1998) were modeled as single compartments and had the following properties: resting membrane potential, $-55 \mathrm{mV}$; Nernst potential for leakage, $-43 \mathrm{mV}$; resistance, $120 \mathrm{M} \Omega$; capacitance, $0.12 \mathrm{nF} ; \mathrm{Na}^{+}$equilibrium potential, $+50 \mathrm{mV} ; \mathrm{K}^{+}$ equilibrium potential, $-80 \mathrm{mV}$; peak conductance of $\mathrm{Na}^{+}$channels, $0.165 \mu \mathrm{S}$; and peak conductance of $\mathrm{K}^{+}$channels, $0.055 \mu \mathrm{S}$.

All neurons had modified Hodgkin-Huxley voltagedependent $\mathrm{Na}^{+}$and $\mathrm{K}^{+}$channels and a passive leak. We used the original formalism of Hodgkin and Huxley (1952) to describe the rate constants for the voltage-dependent $\mathrm{Na}^{+}$and $\mathrm{K}^{+}$channels. The rate constants $\alpha$ and $\beta$ were described by the following:

$$
\alpha, \beta=(A+B E) /\left(C+e^{(E+D) / F}\right),
$$

where $E$ is the membrane potential in millivolts. We modified the constants for $A, B, C, D$, and $F$ used in our previous model for the Xenopus tadpole's spinal central pattern generator (Roberts and Tunstall, 1990) to produce the less negative resting membrane potentials found in whole-cell patch recordings (Li et al., 2004b). To keep the kinetic properties of the membrane unchanged with the resting membrane potential shifted, we used the method described previously (Roberts and Tunstall, 1990) (new values in Table 1). The $\mathrm{Na}^{+}$and $\mathrm{K}^{+}$channel densities were chosen to allow single overshooting spikes up to $+30 \mathrm{mV}$ in response to a broad range of current intensities and postinhibitory rebound (anode break) firing during depolarization. These are features of neurons at the hindbrain-spinal cord border (Fig. 4).

The number of MNs and excitatory (hdIN) and reciprocal iINs per $100 \mu \mathrm{m}$ CNS length (Table 2) and axon lengths were set to mimic the distributions found anatomically (Yoshida et al., 1998; Roberts et al., 1999; Li et al., 2001). They were the same on both sides of the model. However, positions of neurons within each $100 \mu \mathrm{m}$ length were assigned stochastically and independently on the two sides.

\section{Network and synapses}

Our model of the hindbrain-spinal cord border network (Fig. 8) had a length dimension along the body axis $(z)$ and a left and right side. The ipsilateral axons of excitatory neurons and the contralateral axons of inhibitory neurons had ascending and descending branches, which were long enough to reach all neurons on the same or opposite side, respectively. In this model, motoneurons did not make central synapses. Excitatory neurons made synapses onto neurons on the same side, and inhibitory neurons synapsed with neurons on the opposite side. These rules made direct feedback excitation possible among excitatory neurons. Synapses between neurons and passing axons were created in a stochastic manner with certain probabilities (Table 3). Exci- 
tatory and inhibitory neurons use glutamate and glycine in the tadpole, and thus we used these neurotransmitters to refer to the individual properties of these synapses in Table 3.

We modeled three different types of chemical synapses (Table 3): excitatory glutamate synapses and inhibitory glycine synapses. The third type of synapse modeled sensory EPSPs that initiate swimming activity. The conductance changes at synapses were described by a dual exponential function of the following form:

$$
g_{\text {syn }}(t)=A g_{\max }\left(e^{-t / \tau 1}-e^{-t / \tau 2)} /\left(\tau_{1}-\tau_{2}\right),\right.
$$

where $A$ is a normalization constant, chosen so that $g_{\text {syn }}$ reaches a maximum value of $g_{\max }$, and $\tau_{1}$ and $\tau_{2}$ are the opening and closing time constants, respectively. For simplicity, we did not model the following: (1) separate AMPA and NMDA conductances, and the normal voltage dependency of the NMDA channels (Tunstall et al., 2002); and (2) the corelease of glutamate with acetylcholine that we described recently from spinal excitatory neurons ( $\mathrm{Li}$ et al., 2004a).

Long-duration tonic excitation and timed inhibition during this depolarization are essential for sustained rhythmic activity in spinal neurons of young frog tadpoles (Roberts and Tunstall, 1990). Our report presents experimental evidence that tonic depolarization and midcycle inhibition are also present in hindbrain interneurons (Fig. 2E). Therefore, synaptic conductances and probabilities of synapse formation by passing axons in the model were chosen to produce sufficient inhibition to allow neurons to fire rebound action potentials during long-lasting depolarization (Fig. $4 E$ ), following inhibition from the opposite side.

Once the potential in the presynaptic neuron exceeds the spike threshold $(-30 \mathrm{mV})$, there is an axonal conduction delay (3.64 $\mathrm{ms} / \mathrm{mm}$ ) plus synaptic delay (0.5 ms) (Dale and Roberts, 1985), and then the synaptic conductance in the postsynaptic neuron starts to open. The absolute refractory period for spikes was $1 \mathrm{~ms}$.

Activity was initiated by a single pair of sensory pathway EPSPs given to each neuron with a $20 \mathrm{~ms}$ delay between the two sides. Sensory synapses had $15 \mathrm{nS}$ peak conductance; otherwise, they were the same as the glutamate central synapses (Table 3).

\section{References}

Aiken SP, Kuenzi FM, Dale N (2003) Xenopus embryonic spinal neurons recorded in situ with patch-clamp electrodes-conditional oscillators after all? Eur J Neurosci 18:333-343.

Aksay E, Gamkrelidze G, Seung HS, Baker R, Tank DW (2001) In vivo intracellular recording and perturbation of persistent activity in a neural integrator. Nat Neurosci 4:184-193.

Bass AH, Baker R (1990) Sexual dimorphisms in the vocal control system of a teleost fish: morphology of physiologically identified neurons. J Neurobiol 12:155-1168.

Bower JM, Beeman D (1997) The book of genesis. New York: Springer.

Brocard F, Dubuc R (2003) Differential contribution of reticulospinal cells to the control of locomotion induced by the mesencephalic locomotor region. J Neurophysiol 90:1714-1727.

Butt SJB, Lundfald L, Kiehn O (2005) EphA4 defines a class of excitatory locomotor-related interneurons. Proc Natl Acad Sci USA 102:14098-14103.

Collins DF, Burke D, Gandevia SC (2002) Sustained contractions produced by plateau-like behaviour in human motoneurones. J Physiol (Lond) 538:289-301.

Cymbalyuk GS, Gaudry Q, Masino MA, Calabrese RL (2002) Bursting in leech heart interneurons: cell-autonomous and network-based mechanisms. J Neurosci 22:10580-10592.

Dale N, Roberts A (1985) Dual component amino-acid-mediated synaptic potentials: excitatory drive for swimming in Xenopus embryos. J Physiol (Lond) 363:35-59.

Del Negro CA, Morgado-Valle C, Hayes JA, Mackay DD, Pace RW, Crowder EA, Feldman JL (2005) Sodium and calcium current-mediated pace- maker neurons and respiratory rhythm generation. J Neurosci 25:446-453.

Durstewitz D, Seamans JK, Sejnowski TJ (2000) Neurocomputational models of working memory. Nat Neurosci 3 [Suppl]:1184-1191.

Dye JC, Meyer JH (1986) Central control of the electric organ discharge in weakly electric fish. In: Electroreception (Bullock TH, Heiligenberg W, eds), pp 71-102. New York: Wiley.

Fraser DD, MacVicar BA (1996) Cholinergic-dependent plateau potential in hippocampal CA1 pyramidal neurons. J Neurosci 16:4113-4128.

Garcia-Rill E, Skinner RD (1987) The mesencephalic locomotor region. II. Projections to reticulospinal neurons. Brain Res 411:13-20.

Goldman-Rakic PS (1995) Cellular basis of working memory. Neuron 14:477-485.

Hebb DO (1949) The organization of behavior. New York: Wiley.

Hodgkin AL, Huxley AF (1952) A quantitative description of membrane current and its application to conduction and excitation in nerve. J Physiol (Lond) 117:500-544.

Hounsgaard J, Kiehn O (1989) Serotonin-induced bistability of turtle motoneurones caused by a nifedipine-sensitive calcium plateau potential. J Physiol (Lond) 414:265-282.

Kahn JA, Roberts A (1982) The central nervous origin of the swimming motor pattern in embryos of Xenopus laevis. J Exp Biol 99:185-196.

Kawasaki M (1994) The African wave-type electric fish, Gymnarchus niloticus, lacks corollary discharge mechanisms for electrosensory gating J Comp Physiol A Neuroethol Sens Neural Behav Physiol 174:133-144.

Kiehn O (1991) Plateau potentials and active integration in the "final common pathway” for motor behaviour. Trends Neurosci 14:68-73.

Koulakov AA, Raghavachari S, Kepecs A, Lisman JE (2002) Model for a robust neural integrator. Nat Neurosci 5:775-782.

Lee RH, Heckman CJ (1998) Bistability in spinal motoneurons in vivo: systematic variations in rhythmic firing patterns. J Neurophysiol 80:572-582.

Li W-C, Perrins R, Soffe SR, Yoshida M, Walford A, Roberts A (2001) Defining classes of spinal interneuron and their axonal projections in hatchling Xenopus laevis tadpoles. J Comp Neurol 441:248-265.

Li W-C, Soffe SR, Roberts A (2002) Spinal inhibitory neurons that modulate cutaneous sensory pathways during locomotion in a simple vertebrate. J Neurosci 22:10924-10934.

Li W-C, Soffe SR, Roberts A (2004a) Glutamate and acetylcholine corelease at developing synapses. Proc Natl Acad Sci USA 101:15488-15493.

Li W-C, Soffe SR, Roberts A (2004b) A direct comparison of whole cell patch and sharp electrodes by simultaneous recording from single spinal neurons in frog tadpoles. J Neurophysiol 92:380-386.

Li W-C, Higashijima S, Parry DM, Roberts A, Soffe SR (2004c) Primitive roles for inhibitory interneurons in developing frog spinal cord. J Neurosci 24:5840-5848.

Loewenstein Y, Mahon S, Chadderton P, Kitamura K, Sompolinsky H, Yarom Y, Hausser M (2005) Bistability of cerebellar Purkinje cells modulated by sensory stimulation. Nat Neurosci 8:202-211.

Lorente de No R (1938) Analysis of the activity of chains of internuncial neurons. J Neurophysiol 1:207-244.

Major G, Tank D (2004) Persistent neural activity: prevalence and mechanisms. Curr Opin Neurobiol 14:675-684.

Marder E, Calabrese RL (1996) Principles of rhythmic motor pattern generation. Physiol Rev 76:687-717.

Matsuyama K, Mori F, Nakajima K, Drew T, Aoki M, Mori S (2004) Locomotor role of the corticoreticular-reticulospinal-spinal interneuronal system. Prog Brain Res 143:239-249.

McCormick DA, Shu Y, Hasenstaub A, Sanchez-Vives M, Badoual M, Bal T (2003) Persistent cortical activity: mechanisms of generation and effects on neuronal excitability. Cereb Cortex 13:1219-1231.

Mentis GZ, Alvarez FJ, Bonnot A, Richards DS, Gonzalez-Forero D, Zerda R, O’Donovan MJ (2005) Noncholinergic excitatory actions of motoneurons in the neonatal mammalian spinal cord. Proc Natl Acad Sci USA 102:7344-7349.

Metcalfe WK, Mendelson B, Kimmel CB (1986) Segmental homologies among reticulospinal neurons in the hindbrain of the zebrafish larva. J Comp Neurol 251:147-159.

Nieuwkoop PD, Faber J (1956) Normal tables of Xenopus laevis (Daudin). Amsterdam: North Holland.

Nishimaru H, Restrepo CE, Ryge J, Yanagawa Y, Kiehn O (2005) Mamma- 
lian motor neurons corelease glutamate and acetylcholine at central synapses. Proc Natl Acad Sci USA 102:5245-5249.

Noga BR, Kriellaars DJ, Brownstone RM, Jordan LM (2003) Mechanism for activation of locomotor centers in the spinal cord by stimulation of the mesencephalic locomotor region. J Neurophysiol 90:1464-1478.

Nordlander RH, Baden ST, Ryba TM (1985) Development of early brainstem projections to the tail spinal cord of Xenopus. J Comp Neurol 231:519-529.

Ohta Y, Grillner S (1989) Monosynaptic excitatory amino acid transmission from the posterior rhombencephalic reticular nucleus to spinal neurons involved in the control of locomotion in lamprey. J Neurophysiol 62:1079-1089.

Orlovsky GN (1970a) Connexions of the reticulo-spinal neurons with the "locomotor region" of the brain stem. Biophysics 15:178-186.

Orlovsky GN (1970b) Work of the reticulospinal neurons during locomotion. Biophysics 15:761-771.

Pena F, Parkis M, Tryba A, Ramirez J (2004) Differential contribution of pacemaker properties to the generation of respiratory rhythms during normoxia and hypoxia. Neuron 43:105-117.

Perrier J-F, Tresch MC (2005) Recruitment of motor neuronal persistent inward currents shapes withdrawal reflexes in the frog. J Physiol (Lond) 562:507-520.

Peterson BW, Pitts NG, Fukushima K (1979) Reticulospinal connections with limb and axial motoneurons. Exp Brain Res 36:1-20.

Prescott SA, De Koninck Y (2002) Four cell types with distinctive membrane properties and morphologies in lamina I of the spinal dorsal horn of the adult rat. J Physiol (Lond) 539:817-836.

Roberts A (1990) How does a nervous system produce behaviour? A case study in neurobiology. Sci Prog 74:31-51.

Roberts A (2000) Early functional organization of spinal neurons in developing lower vertebrates. Brain Res Bull 53:585-593.

Roberts A, Alford ST (1986) Descending projections and excitation during fictive swimming in Xenopus embryos: neuroanatomy and lesion experiments. J Comp Neurol 250:253-261.

Roberts A, Tunstall MJ (1990) Mutual re-excitation with post-inhibitory rebound: a simulation study on the mechanisms for locomotor rhythm generation in the spinal cord of Xenopus embryos. Eur J Neurosci 2:11-23.

Roberts A, Walford A, Soffe SR, Yoshida M (1999) Motoneurons of the axial swimming muscles in hatchling Xenopus tadpoles: features, distribution, and central synapses. J Comp Neurol 411:472-486.

Satterlie RA (1985) Reciprocal inhibition and postinhibitory rebound pro- duce reverberation in a locomotor pattern generator. Science 229:402-404.

Seung HS, Lee DD, Reis BY, Tank DW (2000) Stability of the memory of eye position in a recurrent network of conductance-based model neurons. Neuron 26:259-271.

Soffe SR (1989) Roles of glycinergic inhibition and $N$-methyl-D-aspartate receptor mediated excitation in the locomotor rhythmicity of one half of the Xenopus embryo central nervous system. Eur J Neurosci 1:561-571.

Soffe SR, Clarke JD, Roberts A (1984) Activity of commissural interneurons in spinal cord of Xenopus embryos. J Neurophysiol 51:1257-1267.

Stein PSG, Grillner S, Selverston AI, Stuart DG (1997) Neurons, networks, and motor behavior. Cambridge, MA: MIT.

Svirskis G, Hounsgaard J (1998) Transmitter regulation of plateau properties in turtle motoneurons. J Neurophysiol 79:45-50.

Tunstall MJ, Roberts A, Soffe SR (2002) Modelling inter-segmental coordination of neuronal oscillators: synaptic mechanisms for uni-directional coupling during swimming in Xenopus tadpoles. J Comp Neurosci 13:143-158.

van Mier P, ten Donkelaar HJ (1989) Structural and functional properties of reticulospinal neurons in the early-swimming stage Xenopus embryo. J Neurosci 9:25-37.

Viana Di Prisco G, Pearlstein E, Robitaille R, Dubuc R (1997) Role of sensory-evoked NMDA plateau potentials in the initiation of locomotion. Science 278:1122-1125.

Viana Di Prisco G, Pearlstein E, Le Ray D, Robitaille R, Dubuc R (2000) A cellular mechanism for the transformation of a sensory input into a motor command. J Neurosci 20:8169-8176.

Wang XJ (2001) Synaptic reverberation underlying mnemonic persistent activity. Trends Neurosci 24:455-463.

Wolf E, Zhao FY, Roberts A (1998) Non-linear summation of excitatory synaptic inputs to small neurones: a case study in spinal motoneurones of the young Xenopus tadpole. 511:871-886.

Yoshida M, Roberts A, Soffe SR (1998) Axon projections of reciprocal inhibitory interneurons in the spinal cord of young Xenopus tadpoles and implications for the pattern of inhibition during swimming and struggling. J Comp Neurol 400:504-518.

Zhao FY, Wolf E, Roberts A (1998) Longitudinal distribution of components of excitatory synaptic input to motoneurones during swimming in young Xenopus tadpoles: experiments with antagonists. J Physiol (Lond) 511:887-901. 